\title{
Covariate determinants of effective dosing regimens for time-dependent beta-lactam antibiotics for critically ill patients
}

\author{
Milan Kaska $^{\mathrm{a}, \mathrm{b}}$, Eduard Havela, , Iva Selke-Krulichova ${ }^{\mathrm{b}}$, Petr Safranek ${ }^{\mathrm{a}}$, Jan Bezouska ${ }^{\mathrm{b}}$, Jirina Martinkova ${ }^{\mathrm{a}}$
}

\begin{abstract}
Aims. Critically ill patients undergoing aggressive fluid resuscitation and treated empirically with hydrosoluble timedependent beta-lactam antibiotics are at risk for sub-therapeutic plasma concentrations. The aim of this study was to assess the impact of two covariates - creatinine clearance $\left(\mathrm{Cl}_{\mathrm{c}}\right)$ and cumulative fluid balance (CFB) on pharmacokinetics/pharmacodynamics (PK/PD) target attainment within a week of treatment with meropenem (ME) or piperacillin/ tazobactam (PIP/TZB).

Methods. In this prospective observational pharmacokinetic (PK) study, 18 critically ill patients admitted to a surgical Intensive Care Unit (ICU) were enrolled. The primary PK/PD target was free antibiotic concentrations above MIC at 100\% of the dosing interval (100\% fT $>$ MIC) to obtain maximum bactericidal activity. Drug concentration was measured using liquid chromatography-tandem mass spectrometry.

Results. The treatment of both 8 septic patients with IV extended ME dosing $2 \mathrm{~g} / 3 \mathrm{~h} \mathrm{q} 8 \mathrm{~h}$ and 10 polytraumatized patients with IV intermittent PIP/TZB dosing 4.0/0.5 $\mathrm{g} \mathrm{q} 8 \mathrm{~h}$ was monitored. 8/18 patients (44\%) manifested augmented renal clearence (ARC) where $\mathrm{Cl}_{\mathrm{cr}} \geq 130 \mathrm{~mL} / \mathrm{min} / 1.73 \mathrm{~m}^{2}$.

Maximum changes were reported on days 2-3: the median positive CFB followed by the large median volume of distribution: $\mathrm{Vd}_{\mathrm{me}}=70.3 \mathrm{~L}$ (41.9-101.5), $\mathrm{Vd}_{\mathrm{pip}}=46.8 \mathrm{~L}$ (39.7-60.0). 100\% $\mathrm{fT}_{\mathrm{me}}>\mathrm{MIC}$ was achieved in all patients on $\mathrm{ME}$ (aged $\geq 60$ years), and only in two patients (non-ARC, aged $\geq 65$ years) out of 10 on PIP/TZB. A mixed model analysis revealed positive relationship of $\mathrm{CFB}_{\text {pip }}$ with $\mathrm{Vd}_{\text {pip }}(P=0.021)$.

Conclusion. Assuming that the positive correlation between CFB and Vd exists for piperacillin in the setting of the pathological state, then $\mathrm{CFB}$ should predict $\mathrm{Vd}_{\text {pip }}$ across subjects at each and every time point.
\end{abstract}

Key words: beta-lactam antibiotics, meropenem, piperacillin, pharmacokinetics/pharmacodynamics target, critically ill patient

Received: November 20, 2017; Accepted: March 21, 2018; Available online: March 27, 2018

https://doi.org/10.5507/bp.2018.011

${ }^{a}$ Department of Surgery, University Hospital Hradec Kralove, Sokolska 581, 50005 Hradec Kralove, Czech Republic

${ }^{b}$ Academic Department of Surgery, Faculty of Medicine in Hradec Kralove, Charles University and Department of Surgery, University Hospital, Sokolska 581, 50005 Hradec Kralove, Czech Republic

Corresponding author: Milan Kaska, e-mail: kaskam@lfhk.cuni.cz

\section{INTRODUCTION}

Critically ill patients undergoing aggressive fluid resuscitation and treated empirically with hydro-soluble $\beta$-lactams piperacillin/tazobactam (PIP/TZB) and meropenem (ME) may be at risk for sub-therapeutic plasma concentrations as a result of non-attainment of PK/PD targets considered crucial for appropriate bactericidal action. The bactericidal effect of these antibiotics is time-dependent, expressed as \% of time in the dosing interval $(\mathrm{T})$ when the plasma concentration of the free drug $(f)$ is elevated above the minimum inhibitory concentration (MIC) for the suspected pathogen - $(\% f \mathrm{~T}>\mathrm{MIC})$. Ideally, this should be $100 \%$ of the dosing interval with maximal bacterial killing achieved at concentrations > one MIC or bacterial eradication achieved at four to five times the MIC (ref. ${ }^{1}$ ).

Nevertheless, PK/PD target attainment (the desired $\% f \mathrm{~T}>\mathrm{MIC}$ ) is dependent on pathophysiological factors (covariates) generated by changes in organ function during the course of the disease in critically ill patients. Extravascular volume expansion with fluid loading and increased capillary permeability may alter the volume of distribution ${ }^{2}$, while changes in renal function can significantly influence drug renal clearance. This covariate might significantly influence hydrophilic drug $\mathrm{Vd}$ and could be a key factor for PK/PD target non-attainment. Therefore, its value could allow prediction of an individual loading dose compensating for extravascular fluid shift during the first days of therapy.

Another important value is the development of augmented renal clearance (ARC) - a phenomenon in which renal excretion of hydro-soluble beta-lactams is increased. ARC is defined by a creatinine clearance $\left(\mathrm{Cl}_{\mathrm{cr}}\right)$ more than or equal to $130 \mathrm{~mL} / \mathrm{min}$ while plasma creatinine concentrations remain normal ${ }^{3}$. For the assessment of ARC, a cut-off of $\mathrm{Cl}_{\text {cr }} \geq 130 \mathrm{~mL} / \mathrm{min}$ normalized by the body surface area (BSA) calculated as weight $(\mathrm{kg})^{0.425} \times$ height $(\mathrm{cm})^{0.725} \times 71.84 / 10000\left(\right.$ ref. $\left.^{4}\right)$ and was used based on previous data demonstrating an association with subtherapeutic B-lactam concentrations, while using standard dosing ${ }^{1,5,6}$. The ARC incidence in critically ill patients is high and varies between $30 \%$ and $85 \%$ (ref. ${ }^{5-9}$ ) depending on the population studied and the cut-off values used for its definition ${ }^{8,10}$ 
Extravascular volume expansion assessed as positive cumulative fluid balance (CFB) was reported in ICU patients undergoing aggressive fluid resuscitation for prevention against hypotension and prolonged vasopressor use ${ }^{11,12}$. This covariate might significantly influence hydrophilic drug Vd and could be a key factor for PK/ PD target non-attainment. Therefore, its value could allow prediction of an individual loading dose compensating for extravascular fluid shift during the first days of therapy.

The primary aim of this study was to verify the impact of covariates, mainly $\mathrm{CFB}$ and $\mathrm{Cl}_{\mathrm{cr}}$ on the $\mathrm{PK} / \mathrm{PD}$ target attainment ( $\% \mathrm{~T}>\mathrm{MIC})$. 7-day monitoring was considered to be long enough to describe the two phases of IV fluid therapy namely Resuscitation and Optimisation aimed at correction of shock and maintenance of tissue perfusion, which are the most important for monitoring, as both intensity and treatment strategy should be individualized ${ }^{11}$.

\section{MATERIALS AND METHODS}

\section{Ethical consideration}

The study protocol was in accordance with the ethical standards laid down in the 2013 Declaration of Helsinki, and was approved by the Ethics Committee of the University Hospital Hradec Králové, Czech Republic in June 27, 2012. All patients or their relatives signed the informed consent before inclusion in the study.

\section{Study patients}

Enrolled in this prospective observational pharmacokinetic study were 18 critically ill patients admitted to the Surgical ICU of the University Hospital in Hradec Králové, Czech Republic. The inclusion criteria were a diagnosis of severe sepsis or septic shock or a systemic inflammatory response (SIRS), together with treatment with a broad-spectrum beta-lactam antibiotic meropenem (ME) respectively piperacillin-tazobactam (PIP/TAZ), provided that the patients signed the informed consent. Patients meeting any of the following criteria were excluded: age less than 18 years or more than 85 years, an expected ICU stay $<24 \mathrm{~h}$, allergy to any of the investigated antibiotics, any evidence of chronic kidney disease or renal replacement therapy, chronic liver disease (cirrhosis or ongoing liver dysfunction with hepatitis) (ref. ${ }^{13,14}$ ). Participants were not allowed to receive any histamine-2-receptor antagonist due to interaction with tubular creatinine secretion ${ }^{15}$.

Patients were admitted to ICU on day 0. Administration of antibiotics was started on day 0 and plasma concentration monitoring was initiated on day 2 (after the fourth to fifth dose), except for patients who underwent some additional treatment (re-operation). In such a case, the start of monitoring was postponed to day 3-4.

The duration of antibiotic monitoring was related to ICU stay and was usually terminated on day 6-7 regardless of the duration of antibiotic treatment.

\section{Dose adjustement}

Antibiotic dosing was administered according to local guidelines for empiric antibiotic therapy. ME was used in the case of suspected colonization by extended spectrum beta-lactamase positive Gram-negative bacteria. Eight patients with peritonitis received an extended infusion dose of $2 \mathrm{~g} \mathrm{ME}$ every $8 \mathrm{~h}$ given by 3 hours IV infusion using a syringe pump via a central venous catheter. Ten polytraumatized patients received empiric intermittent treatment with 4.0/0.5 g PIP/TAZ given by 1-h IV infusion every $8 \mathrm{~h}$ via the same way.

All patients were given IV fluid therapy with balanced crystalloids as early goal-directed therapy ${ }^{12}$. 24 hours (daily) fluid balance (DFB) was recorded as the difference between daily fluid intake and output and the CFB was calculated as the total volume of fluid accumulated over a set period of time ${ }^{11}$.

In all study patients, demographic, pre-existing chronic disease, admission diagnosis and biological data were collected in institutional databases. The severity of illness of each patient was characterized using the Acute Physiology and Chronic Health Evaluation (APACHE II) or the Injury Severity Score (ISS) (ref. ${ }^{16}$ ) and sequential organ failure assessment (SOFA) ( ref. $^{17}$ ). Treatment of patients with catecholamines and mechanical ventilation was recorded, as was duration of ICU and hospital stay. Hemodynamic data were collected as baseline, and 8 and $24 \mathrm{~h}$ after the start of the protocol.

\section{Laboratory analysis}

Serial blood samples were collected over days 2 to 7 as follows: pre-dose, and at 1, 2.5, 4.5 and $6.5 \mathrm{~h}$ post-dose for PIP/TAZ (PIP); pre-dose and at 1, 2.5, and $4.5 \mathrm{~h}$ postdose for ME. Specimens were centrifuged at $3.000 \mathrm{rpm}$ for $10 \mathrm{~min}$ within $30 \mathrm{~min}$ of sampling, and then frozen at $-80{ }^{\circ} \mathrm{C}$ until analysis. Via an indwelling urinary catheter, urine samples were taken at 0-T (over the postdose interval, i.e. between the end of infusion to the next dose administration), and as 24-hour urine collection. The samples were analysed at the Central Laboratory of Clinical Chemistry Department, University Hospital in Hradec Králové using the previously validated method based on liquid chromatography-tandem mass spectrometry (LCMS/MS) (ref. ${ }^{18}$ ). The limits of detection of PIP and ME were $0.003 \mathrm{mg} / \mathrm{L}$ in plasma and urine. The calibration curves for both beta-lactam antibacterials were linear over the concentration range of $0.84-201 \mathrm{mg} / \mathrm{L}$ with correlation coefficient $\left(\mathrm{r}^{2}\right)=0.999$. The limit for quantification was $0.047 \mathrm{mg} / \mathrm{L}$ (for PIP) and $0.048 \mathrm{mg} / \mathrm{L}$ (for ME). Total plasma concentrations were measured. Correction for PIP protein binding (22\%) was based on the published data ${ }^{19}$. Total plasma concentration of ME was not corrected as plasma protein binding is only $2 \%$ and considered not significant.

\section{Pharmacokinetic analysis}

Plasma and urine drug concentrations were used to estimate PK variables using the non-compartmental analysis as follows: the elimination rate constant $\left(\mathrm{k}_{\mathrm{e}}\right)$ was calculated by least-squares linear regression of the loglinear portion of the plasma concentration-time curves, and elimination half-life $\left(\mathrm{t}_{1 / 2}\right)$ was calculated as $0.693 / \mathrm{k}_{\mathrm{e}}$. The area under the plasma concentration-time curve 
$\left(\mathrm{AUC}_{0-\mathrm{T}}\right)$ was obtained using the linear trapezoidal rule. Total (plasma, systemic) clearance $\left(\mathrm{Cl}_{\text {tot }}\right)$ was estimated as dose $/ \mathrm{AUC}_{0-\mathrm{T}}$ and renal clearance $\left(\mathrm{Cl}_{\mathrm{ren}}\right)$ as $\mathrm{Au}_{0-\mathrm{T}} / \mathrm{AUC}_{0-\mathrm{T}}$, where $\mathrm{Au}_{0-\mathrm{T}}$ is the amount of the antibiotic excreted in urine over the postdose interval. Volume of distribution $(\mathrm{Vd})=\mathrm{Cl}_{\text {tot }} / \mathrm{k}_{\mathrm{e}}\left(\right.$ ref. $\left.^{20}\right)$.

The 24-hour creatinine clearance $\left(\mathrm{Cl}_{\mathrm{cr}}\right)$ was measured every study day ${ }^{5} . \mathrm{Cl}_{\mathrm{cr}}=\mathrm{U}_{\mathrm{v}} \times \mathrm{U}_{\mathrm{cr}} /\left(1.440 \times \mathrm{S}_{\mathrm{cr}}\right) \times 1.73 \mathrm{~m}^{2} /$ BSA, where $U_{v}$ is urinary volume, $U_{c r}$ the urinary creatinine concentration $(\mu \mathrm{mol} / \mathrm{L}), \mathrm{S}_{\mathrm{cr}}$ is the serum creatinine concentration in the middle of a sampling period $(\mu \mathrm{mol} / \mathrm{L})\left(\right.$ ref. $\left.^{5}\right)$, and BSA is body surface area.

\section{Pharmacodynamic analysis}

The PK/PD target was free drug concentration maintained above the MIC of the suspected pathogen for $100 \%$ of the dosing interval ( $100 \% f \mathrm{~T}>\mathrm{MIC}$ target $)$, where MIC is a hypothetical target (minimum inhibitory concentration) for the susceptibility breakpoint of the least susceptible microorganisms (wild-type Pseudomonas spp.) for which these antibiotics were used (according to EUCAST) (ref. ${ }^{21}$ ) in accordance with previous studies ${ }^{5,9}$.

\section{PK/PD target attainment}

The percentage time of the free fraction above the MIC ( $\% f$ T $>$ MIC) was evaluated by a graphical method ${ }^{22}$ or calculated using a mathematical expression ${ }^{23}$.

This was defined as $\% f \mathrm{~T}_{\text {pip }}>\mathrm{MIC}(16 \mathrm{mg} / \mathrm{L})$ for PIP and $\% f \mathrm{~T}_{\mathrm{me}}>\mathrm{MIC}(2 \mathrm{mg} / \mathrm{L})$ for ME.

\section{Clinical response testing during the clinical study}

a) Definition of treatment outcome: a/ Positive treatment outcome was completion of the treatment course without change or addition of antibiotic therapy or commencement or additional antibiotics within $48 \mathrm{~h}$ of discontinuation of the antibiotic therapy.

b) The disappearance of all signs related to aseptic or septic SIRS, or improvement in the form of marked or moderate reduction in their severity and number of signs. Clinical parameters of SIRS were evaluated according to SOFA main symptoms: respiratory parameters $\left(\mathrm{FiO}_{2}\right.$, $\mathrm{PaO}_{2}$, and ventilation style), blood parameters (platelets), liver function (bilirubin), central nervous system condition (GCS), cardiovascular parameters (MAP), vasopressors administration, kidney functions (serum and urine creatinine, urine output) - all at the start and on the end of the study.

c) Hemodynamic monitoring and testing the organ functions and return to the normal tissue perfusion: physical examination and review of observations such as peripheral perfusion, oedema, oxygen saturation, and ECG. A daily fluid balance that could be in equilibrium or even negative by the study end (day 7). Fluid balance was considered the essential biomarker of critical illness.

\section{Statistical analysis}

Continuous data are presented as the median (interquartile range). Statistical software package - Sigma Plot 13 SPSS, Inc. Chicago, IL, USA was used for comparison of data between groups and intra-patient data by means of non-paired and paired t-test.

\section{Identification of covariates}

Statistical analysis was performed using the NCSS 9 software - Hintze, J. (2013) NCSS 9. NCSS, LLC. Kaysville, Utah, USA, www.ncss.com (ref. ${ }^{24}$ ). To evaluate changes in both $\% f \mathrm{~T}$ and $\mathrm{Vd}$ during antibiotic treatment and the impact of $\mathrm{CFB}$ and $\mathrm{Cl}_{\text {cr }}$, we used mixed effect models - a general procedure, which allows for repeated measurements. For MER, the day of treatment was entered as a categorical fixed effect, with $\mathrm{CFB}$ and $\mathrm{Cl}_{\mathrm{cr}}$ as covariates. The variable patient was entered as a random effect.

For PIP, the variable day of treatment was entered as a possible covariate together with $\mathrm{CFB}$. The distribution of $\mathrm{Cl}_{\mathrm{cr}}$ values enabled us to divide them into two categories: below $130 \mathrm{~mL} / \mathrm{min} / 1.73 \mathrm{~m}^{2}$ and above this value and enter $\mathrm{Cl}_{\mathrm{cr}}$ as a factor. The patient $\mathrm{x}$ time interaction represented the random model. The significance of the fixed components was tested with an F-test adjusted by Kenward - Roger correction. The significance level was $P \geq 0.05$. If appropriate, Bonferroni adjustment for multiple tests was used.

Table 1. Baseline demographic characteristics and prognostics scoring systems and systemic therapies.

\begin{tabular}{|c|c|c|}
\hline Variable & $\begin{array}{l}\text { Polytrauma } \\
(\mathrm{n}=8)\end{array}$ & $\begin{array}{l}\text { Peritonitis } \\
(\mathrm{n}=10)\end{array}$ \\
\hline Age $(\text { years })^{+}$ & $53.7( \pm 16.5)$ & $69.0( \pm 10.8)$ \\
\hline $\mathrm{M} / \mathrm{F}(\mathrm{n})$ & $6 / 4$ & $8 / 0$ \\
\hline Body weight $(\mathrm{kg})^{+}$ & $80.5( \pm 10.4)$ & $84.1( \pm 15.2)$ \\
\hline $\mathrm{BMI}^{+}$ & $27.1( \pm 3.1)$ & $27.1( \pm 3.5)$ \\
\hline ISS (points)* & $29.5(25.0-75.0)$ & - \\
\hline APACHE II (points)* & - & $24(18.0-27.0)$ \\
\hline SOFA (points) * & $7.5(3-14)$ & $8.0(3-16)$ \\
\hline Vasopressor - noradrenaline IV $(\mu \mathrm{g} / \mathrm{kg} / \mathrm{h})$ * & $13.2(0-62.5)$ & $19.6(0-51.3)$ \\
\hline Artificial ventilation time $(\mathrm{h})$ * & $110(15-744)$ & $62(0-341)$ \\
\hline
\end{tabular}

M-male, F-female, ${ }^{+}$data given as mean $( \pm \mathrm{SD}),{ }^{*}$ data given as median (range) 


\section{RESULTS}

18 patients were enrolled after admission to the Surgical ICU of the University Hospital in Hradec Králové, Czech Republic. The reason for admission was abdominal sepsis $(n=8)$ or polytrauma manifesting SIRS $(n=10)$ (Table 1). Patients suffering from abdominal sepsis were treated with ME and polytraumatized patients were given PIP. Prospective data collection was conducted on study days (over 2-7) dependent on therapeutic procedures (re-operation, special examination). Finally, the study days were stratified into 3 groups including day 2-3, $4-5$, and 6-7, respectively.

Blood samples were taken as follows: one predose and

$\mathbf{a}$

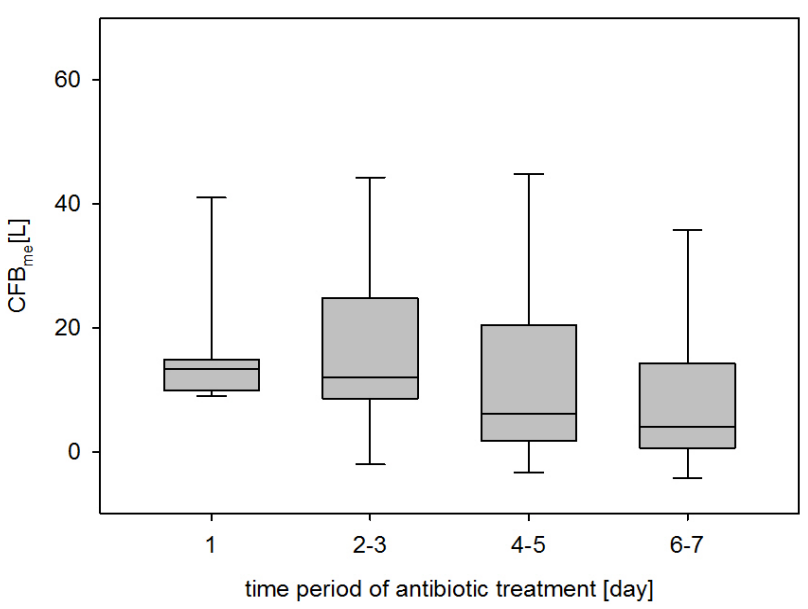

Data presented as Median (interquartiles)

$\mathrm{CFB}_{\mathrm{me}} P=0.02$, day $2-3$ versus day $4-5 . \mathrm{P}=0.002$, day $2-3$ versus day $6-7$. three postdose blood samples (for ME detection) were taken during 3 study days from 8 ICU patients. One predose and four postdose samples (for PIP detection) were taken during 3 study days in 5 ICU patients, and during 2 study days in 5 patients. In total 221 samples were analysed. Urine samples: single concentrations were obtained for each patient from urine collected over the postdose interval and a $24 \mathrm{~h}$ - urine collection per study day. In total 104 urine samples were obtained and analysed.

Eight/18 patients (44\%) manifested ARC $\left(\mathrm{Cl}_{\mathrm{cr}}>130\right.$ $\left.\mathrm{mL} / \mathrm{min} / 1.73 \mathrm{~m}^{2}\right)$ - seven polytrauma subjects, one with sepsis. Three $/ 8$ patients manifested ARC on one occasion during the 7 -study days, $5 / 8$ patients on more than one occasion of $\mathrm{Cl}_{\mathrm{cr}}$ measurements.

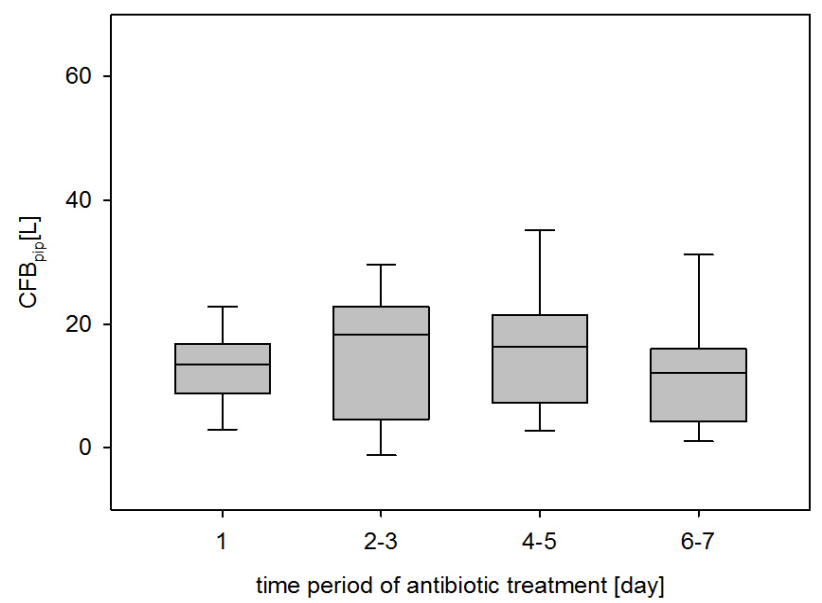

Data presented as Median (interquartiles)

$\mathrm{CFB}_{\text {pip }} P=0.016$, day $2-3$ versus day $6-7$.

Fig. 1. Cumulative fluid balance $(\mathrm{CFB})$ in a/ septic patients treated with meropenem $\left(\mathrm{CFB}_{\mathrm{me}}\right)$ and $\mathrm{b} /$ polytraumatized patients treated with piperacillin/tazobactam $\left(\mathrm{CFB}_{\text {pip }}\right)$ during 7 days.

CFB [L] measured as the difference between fluid input and loss results from increased vascular permeability and fluid loading. The extreme values in $\mathrm{CFB}_{\text {me }}$ were noticed in the patient with the initial $\mathrm{Cl}_{\mathrm{cr}}=9 \mathrm{~mL} / \mathrm{min}$. The median $\mathrm{CFB}_{\mathrm{me}}$ and $\mathrm{CFB}_{\mathrm{pip}}$ reached a maximum on day 2-3 and slowly declined afterwards if fluid therapy was stopped and enhanced vascular permeability returned to a normal state.

a

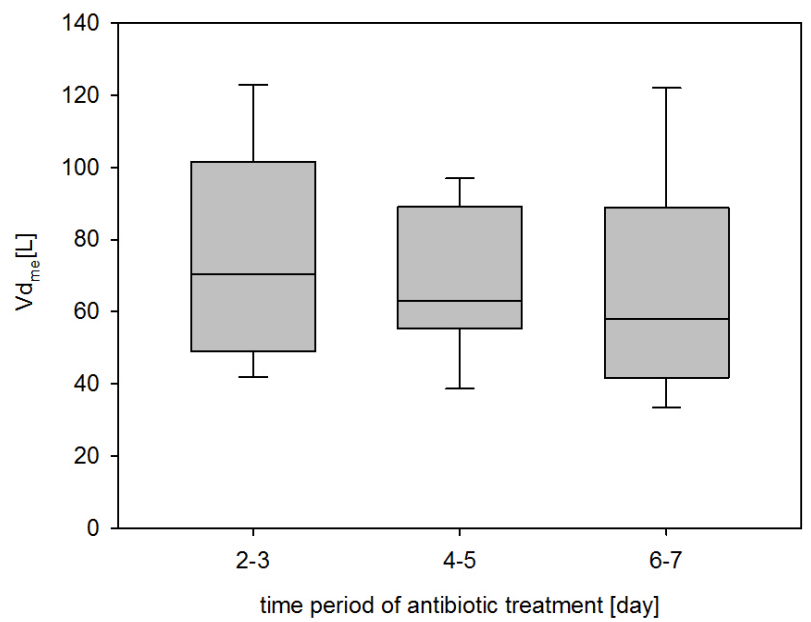

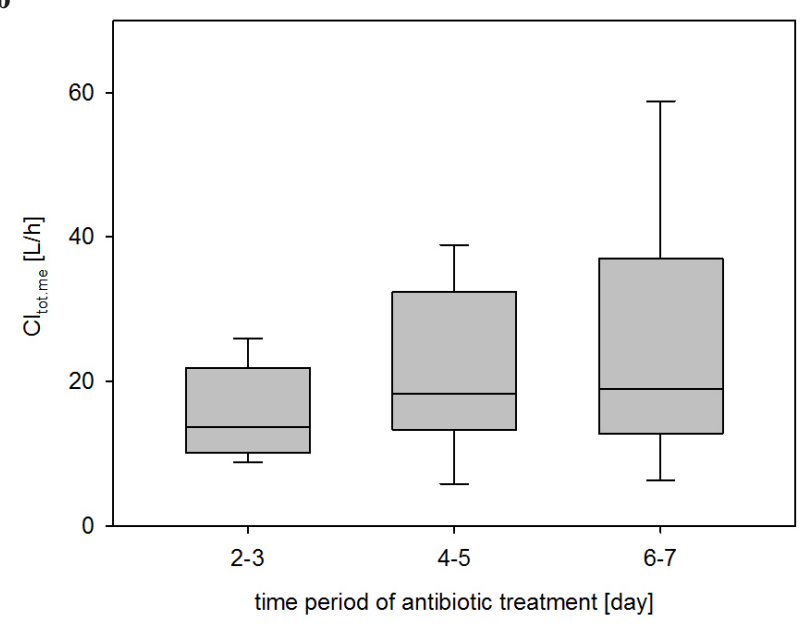

Data presented as Median (interquartiles), $P>0.05$ (NS) for all comparisons

Fig. 2. Meropenem a/ volume of distribution $\left(\mathrm{Vd}_{\text {me }}\right)$ and $\mathrm{b} /$ total clearance $\left(\mathrm{Cl}_{\text {totme }}\right)$ estimated in septic patients treated with meropenem at extended infusion dosing $2 \mathrm{~g}$ over $3 \mathrm{~h}$ every $8 \mathrm{~h}$ for 7 days. 
a

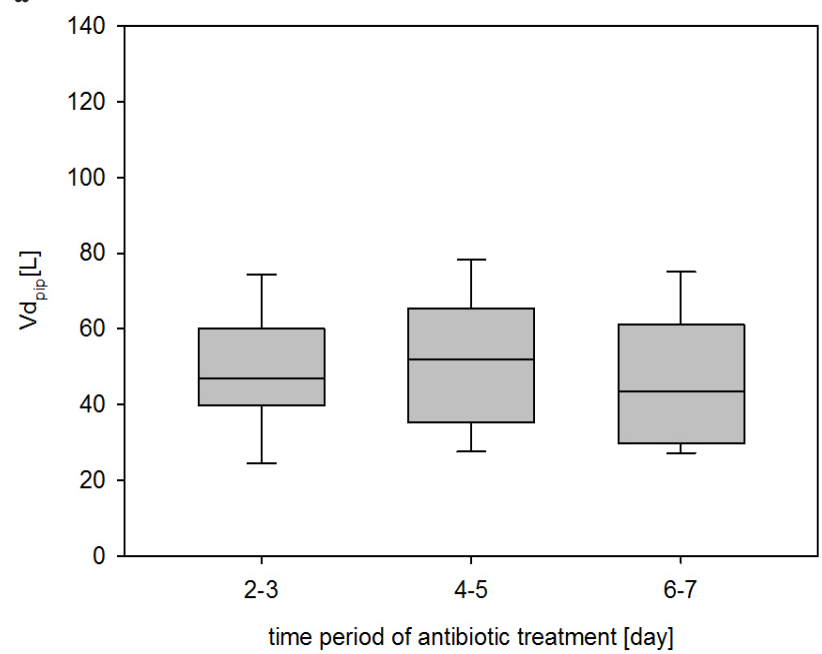

b

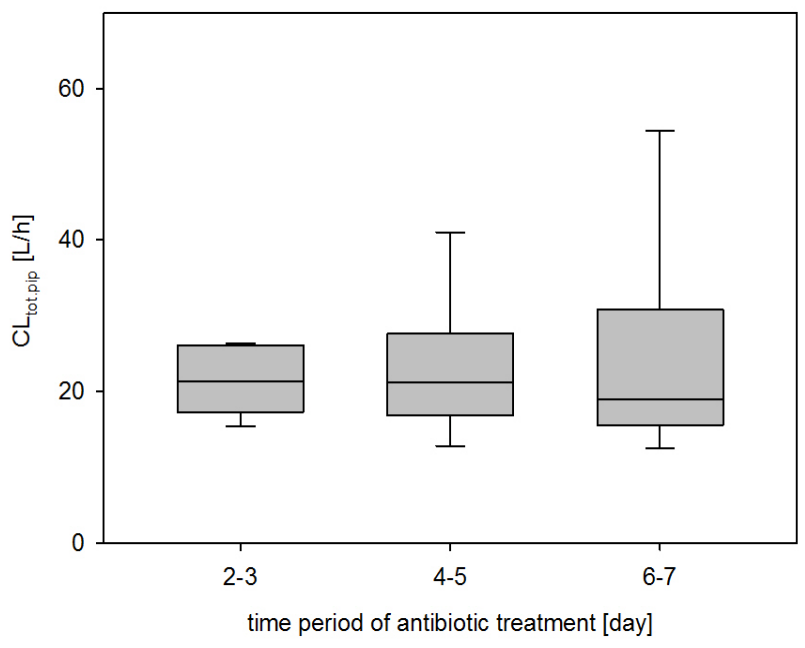

Data presented as Median (interquartiles), $P>0.05$ (NS) for all comparisons

Fig. 3. Piperacillin a/ volume of distribution $\left(\mathrm{Vd}_{\text {pip }}\right)$ and $\mathrm{b} /$ total clearance $\left(\mathrm{Cl}_{\text {tot.pip }}\right)$ estimated in polytraumatized patients treated with piperacillin/tazobactam at intermittent dosing 4.0/0.5 g every $8 \mathrm{~h}$ for 7 days.

No polytrauma patient experienced reduced renal function $\left(\mathrm{Cl}_{\mathrm{cr}}<50 \mathrm{~mL} / \mathrm{min}\right)$.

Among septic patients, $2 / 8$ patients $(25 \%)$ experienced normal renal function $\left(50 \mathrm{~mL} / \mathrm{min}>\mathrm{Cl}_{\mathrm{cr}}<120 \mathrm{~mL} /\right.$ $\min$ ), and $5 / 8$ patients (63\%) had abnormal renal function $\left(\mathrm{Cl}_{\mathrm{cr}}<50 \mathrm{~mL} / \mathrm{min}\right)$. One ARC subject was identified.

The median $\mathrm{CFB}_{\mathrm{me}}$ and $\mathrm{CFB}_{\text {pip }}$ reached a maximum on day 2-3 and slowly declined afterwards when fluid loading was stopped and the high vascular permeability returned to a normal value (Fig. 1a, b). The large median $\mathrm{Vd}_{\mathrm{me}}$ was registered on day 2-3: $70.3 \mathrm{~L}(41.9-101.5)$ (Fig. 2a), i. e. $0.79(0.63-1.0) \mathrm{L} / \mathrm{kg}$. The median $\mathrm{Cl}_{\text {totme }}$ was $15.0 \mathrm{~L} / \mathrm{h}(12.0-20.8)$ on day $2-3$ (Fig. $2 \mathrm{~b}$ ), while the median $\mathrm{Cl}_{\text {ren.me }}$ reached only $44.5 \%(28.0-54.5)$ of $\mathrm{Cl}_{\text {totme }}$. The median half-life of elimination $\left(\mathrm{T}_{1 / 2 \mathrm{me}}\right)$ reached $3.5 \mathrm{~h}$ on day $2-3$, and subsequently $2.5 \mathrm{~h}$ on day $6-7$ $(P=0.029)$. The predefined target $100 \% f \mathrm{~T}>2 \mathrm{mg} / \mathrm{L}$ was attained in all patients including $1 / 8$ of patients who attained $4 \mathrm{MIC}>100 \% \mathrm{f}<8 \mathrm{MIC}$, and $2 / 8$ who experienced $100 \% f \mathrm{~T}>8 \mathrm{MIC}$. The median $\% f \mathrm{~T}$ was declining towards the termination of antibiotic monitoring (day 7).

The median $\mathrm{CFB}_{\text {pip }}$ reached a maximum $18.2 \mathrm{~L}$ (4.6-22.8) on day $2-3$ of treatment and slowly declined (Fig. 1b). Simultaneously the median $\mathrm{Vd}_{\text {pip }}$ attained 46.8 (39.7-60.0) L, i.e. $0.63(0.56-0.78) \mathrm{L} / \mathrm{kg}$ and slowly declined during next days of treatment (Fig. 3a). The median $\mathrm{Cl}_{\text {tot.pip }}$ was $21.3(18.4-24.3) \mathrm{L} / \mathrm{h}$, and that of $\mathrm{Cl}_{\text {ren,pip }}$ - $15.6(14.3-17.1) \mathrm{L} / \mathrm{h}$ - reached $72(63-81) \%$ of the former. No significant decrease in drug clearance occurred over a 7-day treatment. $\mathrm{T}_{1 / 2 \text {.pip }}$ was reduced from 1.7 hour (on day 2-3) to 1.4 hour (on day 6-7) $(P=0.043)$.

The predefined target $100 \% \mathrm{f}>16 \mathrm{mg} / \mathrm{L}$ was attained only in two non-ARC patients (aged 65 and 67 years). $50 \% f \mathrm{~T}$ and $30 \% f \mathrm{~T}$ were attained in $5 / 10$ subjects and $3 / 10$ subjects, respectively. Seven patients with sub-therapeutic plasma concentration were ARC subjects.

\section{The impact of two covariates - $\mathrm{Cl}_{\mathrm{cr}}$ and CFB on $\% \mathrm{fT}$ and antibiotic Vd}

The mixed model analysis of PIP data revealed a statistically significant difference in $\% \mathrm{fT}$ pip for two categories of $\mathrm{Cl}_{\mathrm{cr}}\left(\mathrm{Cl}_{\mathrm{cr}}>130 \mathrm{~mL} / \mathrm{min}\right.$ and $\left.\mathrm{Cl}_{\mathrm{cr}}<130 \mathrm{~mL} / \mathrm{min}\right)(P=0.0018)$ (Table 2). Also, the analysis of ME data showed a significant inverse relationship between $\% \mathrm{fT}_{\mathrm{me}}$ and $\mathrm{Cl}_{\mathrm{cr}}: \% \mathrm{fT}_{\text {me }}$ declined with elevated value of $\mathrm{Cl}_{\mathrm{cr}}(P=0.012)$ (Table 3). There was non-significant relationship between $\mathrm{CFB}_{\text {me }}$ and $\mathrm{Vd}_{\text {me }}(P=0.10)$ (Table 3$)$, while $\mathrm{Vd}_{\text {pip }}$ became much larger with a higher value of CFB $(P=0.021)$ (Table 2$)$.

\section{Clinical response to treatment}

a. During patients ICU stay (terminated by day 7-10), there was no modification of antibiotic therapy.

b. The initial clinical or laboratory data describing the patient states are given in Table 1. By the end of 7-day monitoring the score value of SOFA - median (range) in patients suffering from polytrauma dropped as follows $7.5(3-14)$ to $2(2-9), P<0.001$ and in abdominal peritonitis $8(3-16)$ to $2.5(0-8), P<0.001$.

No patient died within the stay in the ICU so as later.

\section{DISCUSSION}

This study demonstrates significant higher values of the Vd of both betalactam antibiotics given to the ICU patients if compared with data reported for healthy volunteers or less seriously ill patients ${ }^{25-28}$. The impact of age and decreasing $\mathrm{Cl}_{\mathrm{cr}}\left(\right.$ ref. $\left.^{29}\right)$ was noticed in renal clearance estimation. Values of the median $\mathrm{Cl}_{\text {tot,me }}$ and that of $\mathrm{Cl}_{\text {tot,pip }}$ were higher than that estimated in healthy volunteers ${ }^{30}$, and compatible with patients ' data ${ }^{31}$ in the septic patients $>60$ year old, $\mathrm{Cl}_{\text {ren,me }}$ reached only $44.5 \%$ of $\mathrm{Cl}_{\text {tot,me }}$ and indicated the augmented extrarenal clearance in critically 
Table 2. Piperacillin. Description of fixed effects in models for $\% f \mathrm{~T}_{\mathrm{pip}}$ and $\mathrm{Vd}_{\mathrm{pip}}$.

\begin{tabular}{|c|c|c|c|c|c|}
\hline \multirow{2}{*}{ Effect Name } & \multirow{2}{*}{$\begin{array}{l}\text { Effect Estimate } \\
\text { (Beta) }\end{array}$} & \multirow{2}{*}{$\begin{array}{c}\text { Effect Standard } \\
\text { Error }\end{array}$} & \multirow{2}{*}{$P$} & \multicolumn{2}{|c|}{$95 \% \mathrm{CI}$} \\
\hline & & & & Lower Limit & Upper Limit \\
\hline \multicolumn{6}{|l|}{ Fixed effects for $\% f \mathrm{~T}_{\text {pip }}$} \\
\hline Intercept & 28.52 & 8.96 & 0.005 & 9.81 & 47.23 \\
\hline Day of treatment & 0.41 & 1.44 & 0.777 & -2.61 & 3.43 \\
\hline CFB & 1.26 & 0.34 & 0.001 & 0.55 & 1.97 \\
\hline $\mathrm{Cl}_{\mathrm{cr}}<130 \mathrm{~mL} / \mathrm{min}$ & 20.70 & 5.71 & 0.002 & 8.75 & 32.65 \\
\hline $\mathrm{Cl}_{\mathrm{cr}}^{\mathrm{cr}}>130 \mathrm{~mL} / \mathrm{min}$ & 0 & 0 & & & \\
\hline \multicolumn{6}{|l|}{ Fixed effects for $\mathrm{Vd}_{\mathrm{pip}}$} \\
\hline Intercept & 0.47 & 0.17 & 0.012 & 0.11 & 0.83 \\
\hline $\mathrm{Cl}_{\mathrm{cr}}<130 \mathrm{~mL} / \mathrm{min}$ & -0.03 & 0.12 & 0.832 & -0.27 & 0.22 \\
\hline $\mathrm{Cl}_{\mathrm{cr}}>130 \mathrm{~mL} / \mathrm{min}$ & 0 & 0 & & & \\
\hline Day of treatment & -0.01 & 0.03 & 0.708 & -0.07 & 0.05 \\
\hline CFB & 0.02 & 0.01 & 0.021 & 0.00 & 0.03 \\
\hline
\end{tabular}

Table 3. Meropenem. Description of fixed effects in models for $\% f \mathrm{~T}_{\mathrm{me}}$ and $\mathrm{Vd}_{\mathrm{me}}$.

\begin{tabular}{|c|c|c|c|c|c|}
\hline \multirow{2}{*}{ Effect Name } & \multirow{2}{*}{$\begin{array}{l}\text { Effect Estimate } \\
\text { (Beta) }\end{array}$} & \multirow{2}{*}{$\begin{array}{c}\text { Effect Standard } \\
\text { Error }\end{array}$} & \multirow{2}{*}{$P$} & \multicolumn{2}{|c|}{$95 \% \mathrm{CI}$} \\
\hline & & & & Lower Limit & Upper Limit \\
\hline \multicolumn{6}{|l|}{ Fixed effects for $\% f T_{m e}$} \\
\hline Intercept & 514.38 & 112.82 & 0.003 & 247.31 & 781.46 \\
\hline day of treatment $=2$ & -64.16 & 71.43 & 0.384 & -217.17 & 88.85 \\
\hline day of treatment $=4$ & 63.89 & 67.12 & 0.359 & -81.08 & 208.85 \\
\hline day of treatment $=6$ & 0 & 0 & & & \\
\hline $\mathrm{Cl}_{\mathrm{cr}}$ & -4.51 & 1.30 & 0.012 & -7.63 & -1.39 \\
\hline CFB & 6.49 & 2.87 & 0.071 & -0.78 & 13.76 \\
\hline \multicolumn{6}{|l|}{ Fixed effects for $\mathrm{Vd}_{\text {me }}$} \\
\hline Intercept & 25.82 & 23.86 & 0.319 & -31.81 & 83.45 \\
\hline day of treatment $=2$ & 2.06 & 13.97 & 0.884 & -27.64 & 31.77 \\
\hline day of treatment $=4$ & -6.22 & 12.38 & 0.624 & -32.96 & 20.53 \\
\hline day of treatment $=6$ & 0 & 0 & & & \\
\hline $\mathrm{Cl}_{\mathrm{cr}}$ & 0.44 & 0.26 & 0.150 & -0.22 & 1.10 \\
\hline CFB & 1.24 & 0.61 & 0.105 & -0.38 & 2.85 \\
\hline
\end{tabular}

ill older patients also reported by others ${ }^{25}$. This outcome is considered a consequence of increased exposure to dehydropeptidase 1 , causing nonspecific hydrolysis in tissue to an inactive metabolite ${ }^{27}$.

The primary PK/PD target were free antibiotic concentrations above the MIC at $100 \%$ of the dosing interval (100\% $\mathrm{T}>\mathrm{MIC}$ ). As demonstrated above, 7-study day monitoring revealed that intermittent dosing 4.0/0.5 g q8h of PIP, and extended infusion dosing $2.0 \mathrm{~g} / 3 \mathrm{~h}$ q $8 \mathrm{~h}$ of ME was sufficient for obtaining this predefined exposure in non-ARC patients aged $\geq 60$ year, approximately, but was not achieved in younger ARC patients in accordance with previous reports ${ }^{5,27}$. If fourfold the MIC is the target of intervention, then $\% f \mathrm{~T}_{\text {me }}$ ranges $40-100 \%$ with low values within $40-70 \%$ attributed to 3 patients with normal or augmented renal clearance. Accordingly, $\% f \mathrm{~T}_{\text {pip }}$ is within $8-26 \%$.

This failure after conventional dosing is considered a result of sub-therapeutic plasma concentration-time profiles and changes in $\mathrm{PK}$ parameters ( $\mathrm{Vd}$ and $\mathrm{Cl}$ ), affected by two main covariates: $\mathrm{Cl}_{\mathrm{cr}}$ and positive CFB. Positive $\mathrm{CFB}$ (reflecting extravascular volume expansion) results from increased capillary permeability and IV fluid loading which is widely regarded as the first step in the resuscitation of critically ill and injured patients who have evidence of impaired organ perfusion. The present study shows a rapid increase in $C F B$ during days $0-1$ culminating on days $2-3$, that is followed by a large value of $\mathrm{Vd}$ of $\mathrm{ME}$ and PIP. A normal value of $\mathrm{Vd}$ reflecting both the dose and extracellular distribution usually ranges $0.2-0.4 \mathrm{~L} /$ $\mathrm{kg}$. In a pathological setting this value can exceed the real extracellular fluid volume as a result of higher penetration into intraabdominal and pulmonary tissues, skin or peritoneal fluids, or may reflect higher tissue binding ${ }^{25,32}$. Thus positive CFB underlines the importance of individual dosing that would compensate an intravascular drug deficit due to extravascular volume expansion.

This study also denotes the impact of two pathological models - polytrauma and sepsis - on kinetic variables mediated via the covariates. CFB correlated with $\mathrm{Vd}_{\text {pip }}$ (in polytraumatized patients), while not with $\mathrm{Vd}_{\text {me }}$ (in sepsis). This difference can be attributable to the patient (age, renal function), to the properties of a drug and especially to the pathological setting. It seems that positive correlation between CFB and Vd does not develop in the pathological state suppressing renal functions as shown via $\mathrm{Cl}_{c r}$. 
Therefore, we cannot exclude a significant relationship between $\mathrm{CFB}_{\mathrm{me}}$ and $\mathrm{Vd}_{\mathrm{me}}$ that could be registered in a study conducted with numerous patients who experience normal or augmented renal clearance.

The influence of $\mathrm{Cl}_{\mathrm{cr}}$ may be bidirectional: high $\mathrm{Cl}_{\mathrm{cr}}$ predicts non-achievement of the predefined $\% f \mathrm{~T}\left(\right.$ ref. $\left.^{5,22}\right)$ and failure of antibiotic therapy as shown in patients treated with conventional dosing of piperacillin. Reduced $\mathrm{Cl}_{\mathrm{cr}}$ and consequent low antibiotic $\mathrm{Cl}_{\text {ren }}$ can result in drug accumulation $^{22,30}$ and elevated $\% f$ T. Unfortunately, $\mathrm{Cl}_{\mathrm{cr}}$ was shown to be a covariate not predictive of variations in drug PK/PD target attainment in such setting ${ }^{33}$. Is CFB next covariate that should be taken into consideration as the predictor of the first (loading) doses and that presented by $\mathrm{Cl}_{\mathrm{cr}}$ as the predictor of next dosing adaptation?

\section{Limitation}

This study has a number of limitations. First, only a small number of patients were eligible, even if these subjects were monitored 2-3times a 7-day treatment. Secondly, $\% f \mathrm{~T}$ was based on 1-week empirical treatment with broad spectrum beta-lactams and MIC obtained from EUCAST, but de-escalation does not seem to resolve the problem of under-dosing. The probability that therapeutic exposure of critically ill patients would be achieved was shown even lower for narrower-spectrum antibiotics with conventional dosing than that for the broad-spectrum drugs $^{34}$. Thirdly, the target attainment defined as $100 \% f \mathrm{~T}$ $>\mathrm{MIC}$ and/or $100 \% \mathrm{fT}>4 \mathrm{MIC}$ should be analysed since the first $24 \mathrm{~h}$ of treatment.

This aside, we believe that a more detailed analysis of the relationship between $\mathrm{Vd}$ a CFB and its practical use is worth studying next. Fluid balance as a predictor of drug Vd available at the bedside would help critically ill ICU patients, who require adequate dosing within $24 \mathrm{~h}$ after the start of treatment and /or next dose adaptation ${ }^{35}$.

\section{CONCLUSION}

Assuming that the positive correlation between CFB and $\mathrm{Vd}$ exists for piperacillin in the pathological setting, then CFB should predict Vd across subjects at each and every time point. The authors recommend to use two times higher starting dose of piperacilin/tazobactam and $100 \% f \mathrm{~T}>4 \mathrm{MIC}$ for $\mathrm{PK} / \mathrm{PD}$ target attainment in critically ill patient undergoing aggressive fluid resuscitation than in standard type of patient.

\section{ABBREVIATIONS}

$\% f \mathrm{~T}$, the percentage time during the dosing interval (T) where the free (unbound) drug concentration $(f)$ remained above the MIC of the suspected pathogen; APACHE II, Acute physiology and chronic health evaluation II; ARC, Augmented renal clearance; AUC, Area under the curve; BSA, Body surface area; $\mathrm{Cl}_{\text {ren }}$, Renal clearance; $\mathrm{Cl}_{\mathrm{cr}}$, Creatinine clearance; $\mathrm{Cl}_{\text {tot }}$, Total (plasma) body clearance; CFB, Cumulative fluid balance; DFB,
Daily fluid balance; EUCAST, European committee for antibiotic testing; GSS, Glasgow coma scale; ICU, Intensive care unit; $\mathrm{k}_{\mathrm{e}}$, Elimination rate constant; ISS, Injury severity score; LC-MS/MS, Liquid chromatography coupled to tandem mass spektrometry; MAP, Medial arterial pressure; ME, Meropenem; MIC, Minimal inhibitory concentration; PIP, Piperacilin/tazobactam; PD, Pharmacodynamics; PK, Pharmacokinetics; $S_{c r}$, Serum creatinine concentration; SIRS, Systemic inflammatory response syndrome; SOFA, Sequential organ failure assessment; Vd, Volume of distribution.

Acknowledgment: Authors are grateful to the Internal Grand Agency (IGA) of Ministry of Health, Czech Republic, project No.NT14089-3/2013 and to the institutional project PROGRES Q40/04 of the Charles University, Prague, the nursing staff of Surgical Dept. ICU, and to Ms. Hana Krupickova for excellent laboratory assistance.

The authors are grateful to Ian McColl MD, PhD for assistance with the manuscript.

Author contributions: As the principal investigator, MK had full access to all study data and takes responsibility for the integrity of the data and the accuracy of the data analysis in tight cooperation with JM. Study concept and design were performed by EH, PS, and JM. Drafting of the manuscript was executed by MK and JM. ISK was focused on statistical analysis of results. JB cooperated in graphic tasks and IT processes. Critical revision of the manuscript was done by MK and JM. All authors checked and approved the final manuscript.

Availability of data and materials: All data, that is included in the analysis and from which the conclusions are drawn, are available in the Department of Surgery, Teaching Hospital, Sokolská 581, 50005 Hradec Králové, Czech Republic.

Conflict of interest statement: The authors state that there are no conflicts of interest regarding the publication of this article.

\section{REFERENCES}

1. Udy AA, Varghese JM, Altukroni M, Briscoe S, McWhinney BC, Ungerer JP, Lipman J, Roberts JA. Subtherapeutic initial $\beta$-lactam concentrations in select critically ill patients: association between augmented renal clearance and low trough drug concentrations. Chest 2012;142:30-9.

2. Eyler RF, Mueller BA. Antibiotic dosing in critically ill patients with acute kidney injury. Nat Rev Nephrol 2011;7:226-35.

3. Udy AA, Roberts JA, Shorr AF, Boots RJ, Lipman J. Augmented renal clearance in septic and traumatized patients with normal plasma creatinine concentrations: identifying at-risk patients. Crit Care 2013;17:R35.

4. Hoste EA, Damen J, Vanholder RC, Lameire NH, Delanghe JR, Van den Hauwe K, Colardyn FA. Assessment of renal function in recently admitted critically ill patients with normal serum creatinine. Nephrol Dial Transplant 2005;20:747-53.

5. Carlier M, Carrette S, Roberts JA, Stove V, Verstraete A, Hoste E, Depuydt P, Decruyenaere J, Lipman J, Wallis SC, De Waele JJ. Meropenem and piperacillin/tazobactam prescribing in critically ill patients: does augmented renal clearance affect pharmacokinetic/ pharmacodynamic target attainment when extended infusions are used? Crit Care 2013;17:R84. http: //ccforum.com/content/17/3/ R84. 
6. Hobbs AL, Shea KM, Roberts KM, Daley MJ. Implications of Augmented Renal Clearance on Drug Dosing in Critically III Patients: A Focus on Antibiotics. Pharmacotherapy 2015;35:1063-75.

7. Claus BO, Hoste EA, Colpaert K, Robays H, Decruyenaere J, De Waele $J$ J. Augmented renal clearance is a common finding with worse clinical outcome in critically ill patients receiving antimicrobial therapy. Crit Care 2013;28:695-700.

8. Udy AA, Baptista JP, Lim NL, Joynt GM, Jarrett P, Wockner L, Boots $\mathrm{RJ}$, Lipman J. Augmented renal clearance in the ICU: results of a multicenter observational study of renal function in critically ill patients with normal plasma creatinine concentrations. Crit Care Med 2014;42:520-7.

9. De Waele JJ, Lipman J, Akova M, Bassetti M, Dimopoulos G, Kaukonen M, Koulenti D, Martin C, Montravers P, Rello J, Rhodes A, Udy AA, Starr T, Wallis SC, Roberts JA. Risk factors for target non-attainment during empirical treatment with $\beta$-lactam antibiotics in critically ill patients. Intensive Care Med 2014;40:1340-51.

10. Minville V, Asehnoune K, Ruiz S, Breden A, Georges B, Seguin T, Tack I, Jaafar A, Saivin S, Fourcade O, Samii K, Conil JM. Increased creatinine clearance in polytrauma patients with normal serum creatinine: a retrospective observational study. Crit Care 2011;15:R49.

11. Malbrain M, Marik PE, Witters I, Cordemans C, Kirkpatrick AW, Roberts DJ, Van Regenmortel N. Fluid overload, de-resuscitation, and outcomes in critically ill or injured patients: a systematic review with suggestions for clinical practice. Anaesthesiol Intensive Ther 2014;46:361-80.

12. Rivers E, Nguyen B, Havstad S, Ressler J, Muzzin A, Knoblich B, Peterson E, Tomlanovich M. Early Goal-Directed Therapy in the treatment of severe sepsis and septic shock. N Engl J Med 2001;345:136877.

13. Hull JH, Hak LJ, Koch GG, Wargin WA, Chi SL, Mattocks AM. Influence of range of renal function and liver disease on predictability of creatinine clearance. Clin Pharmacol Ther 1981;29:516-21.

14. Papadakis MA, Arieff AI. Unpredictability of clinical evaluation of renal function in cirrhosis. Prospective study. Am J Med 1987;82:945 52.

15. Larsson R, Bodemar G, Kågedal B, Walan A. The effects of cimetidine (Tagamet) on renal function in patients with renal failure. Acta Med Scand 1980;208:27-31.

16. Hahn RG. Volume kinetics for infusion fluids. Anesthesiology 2010;113:470-81.

17. Vincent JL, De Backer D. Circulatory shock. N Engl J Med 2013;369:1726-34.

18. Ohmori T, Suzuki A, Niwa T, Ushikoshi H, Shirai K, Yoshida S, Ogura S Itoh Y. Simultaneous determination of eight $\beta$-lactam antibiotics in human serum by liquid chromatography-tandem mass spectrometry. J Chromatogr B Analyt Technol Biomed Life Sci 2011; 879:1038 42.

19. Clinical investigators brochure - American Cyanamid Co., Lederle Laboratories Div., Pearl River, N.Y. 1977.
20. Hedaya MA. Basic Pharmacokinetics. CRC Press pharmacy education series. Taylor \& Francis Group: Boca Raton - London - New York; 2007.

21. Clinical breakpoints. European Committee on Antimicrobial Susceptibility Testing (EUCAST) - http//www.eucast.org/

22. Martínková J, Malbrain M, Havel E, Šafránek P, Bezouška J, Kaška M. A pilot study on pharmacokinetic/pharmacodynamic target attainment in critically ill patients receiving piperacillin/tazobactam. Anaesthesiol Intensive Ther 2015;48:23-8.

23. Kim MK, Xuan D, Quintiliani $R$, Nightingale $C H$, Nicolau DP. Pharmacokinetic and pharmacodynamic profile of high dose extended interval piperacillin-tazobactam. Antimicrob Chemother 2001;48:259-67.

24. Hintze, J. NCSS 9. NCSS, LLC. Kaysville, Utah, USA. 2013. (www.ncss. com)

25. Baldwin CM, Lyseng-Williamson KA, Keam SJ. Meropenem: a review of its use in the treatment of serious bacterial infections. Drugs 2008;68:803-38.

26. Bedikian A, Okamoto MP, Nakahiro RK, Farino J, Heseltine PN, Appleman MD, Yellin AE, Berne TV, Gill MA. Pharmacokinetics of meropenem in patients with intra-abdominal infections. Antimicrob Agents Chemother 1994; 38:151-4.

27. Binder L, Schworer H, Hoppe S, Streit F, Neumann S, Beckmann A Wachter R, Oellerich M, Walson PD. Pharmacokinetics of meropenem in critically ill patients with severe infections. Ther Drug Monit 2013;35:63-70.

28. Novelli A, Adembri C, Livi P, Fallani S, Mazzei T, De Gaudio AR. Pharmacokinetic evaluation of meropenem and imipenem in critically ill patients with sepsis. Clin Pharmacokinet 2005;44:539-49.

29. Mouton JW, van den Anker JN. Meropenem clinical pharmacokinetics. Clin Pharmacokinet 1995;28:275-86.

30. Hayashi Y, Roberts JA, Paterson DL, Lipman J. Pharmacokinetic evaluation of piperacillin-tazobactam. Expert Opin Drug Metab Toxicol 2010;6:1017-31.

31. Roberts JA, Ulldemolins M, Roberts MS, McWhinney B, Ungerer J, Paterson DL, Lipman J. Therapeutic drug monitoring of beta-lactams in critically ill patients: proof of concept. Int J Antimicrob Agents 2010;36:332-9.

32. Nicolau DP. Pharmacokinetic and pharmacodynamic properties of meropenem. Clin Infect Dis 2008;47(S1):S32-40.

33. Casu GS, Hites M, Jacobs F, Cotton F, Wolff F, Beumier M, De Backer D, Vincent JL, Taccone FS. Can changes in renal function predict variations in $\beta$-lactam concentrations in septic patients? Int J Antimicrob Agents 2013;42:422-8.

34. Carlier M, Roberts JA, Stove V, Verstraete AG, Lipman J, De Waele JJ. A simulation study reveals lack of pharmacokinetic/pharmacodynamic target attainment in de-escalated antibiotic therapy in critically ill patients. Antimicrob Agents Chemother 2015;59:4689-94.

35. Elbers PWG, Girbes A, Malbrain MLNG, Bosman R. Right dose, right now: using big data to optimize antibiotic dosing in the critically ill. Anaesthesiol Intensive Ther 2015;47:457-63. 